\title{
DOCTRINA DEL TJUE SOBRE LA INMUNIDAD DE EJECUCIÓN DE LAS ORGANIZACIONES INTERNACIONALES Y EL ÁMBITO DE APLICACIÓN DEL REGLAMENTO BRUSELAS I BIS*
}

\section{DOCTRINE OF THE CJEU ON THE IMMUNITY OF EXECUTION OF INTERNATIONAL ORGANIZATIONS AND THE FIELD OF APPLICATION OF THE BRUSSELS I BIS REGULATION}

\author{
LuCAs ANDRÉs PéRez MarTín \\ Profesor Contratado Doctor de Derecho internacional privado \\ Universidad de Las Palmas de Gran Canaria \\ ORCID: 0000-0001-6340-0528
}

Recibido: 09.12.2020 / Aceptado: 21.12.2020

DOI: https://doi.org/10.20318/cdt.2021.6012

\begin{abstract}
Resumen: En el año 2020 el TJUE ha enmarcado en dos importantes resoluciones los tipos de acciones en los que los negocios jurídicos de los estados o las organizaciones internacionales con personas del derecho privado se comprenden dentro del ámbito de aplicación del Reglamento Bruselas I bis como materia civil y mercantil y no están amparados por el principio de Derecho internacional de inmunidad de jurisdicción y ejecución. En el presente trabajo analizamos la Sentencia 3 septiembre 2020, que resuelve un procedimiento en el que la OTAN alegaba que el contrato de depósito de aseguramiento de los pagos de un contrato de suministro de combustible para asistir a la operación desarrollada en Afganistán tras los atentados de 2001 estaba amparado por el principio de inmunidad de ejecución, lo que negó el TJUE.

Palabras clave: inmunidad de jurisdicción, inmunidad de ejecución, materia civil y mercantil, contrato de depósito, embargo provisional.
\end{abstract}

Abstract: In 2020 the CJEU has framed in two important resolutions the types of actions in which the legal business of states or international organizations with private law persons are included within the framework of the Brussels I bis Regulation under the domain of civil and commercial maters and are not covered by the principle of international law of immunity from jurisdiction and enforcement. In the present paper we analyze the Judgment of September 3, 2020, which resolves a procedure in which NATO alleged that the deposit contract to ensure the payments of a fuel supply contract to assist the operation carried out in Afghanistan after The 2001 attacks, were protected by the principle of immunity from execution, which the CJEU denied.

Keywords: immunity from jurisdiction, immunity from execution, civil and commercial matters, deposit agreement, provisional attachment.

Sumario: I. El negocio jurídico y la finalidad, la compra de combustible para una operación internacional. II. El ámbito de aplicación de Bruselas I bis y la inmunidad de ejecución. 1. Ámbito

\footnotetext{
*Este trabajo ha sido realizado en el marco del Proyecto de Investigación I+D+I: "Obstáculos a la movilidad de personas en los nuevos escenarios de la UE”, financiado por el Ministerio de Economía y Competitividad, Dirección General de Investigación Científica y Técnica, con la referencia DER2017-86017-R.

**1ucas.perez@ulpgc.es.
} 
de aplicación material y civil y contrato de suministro militar. 2. La inmunidad de ejecución de una organización internacional ante un impago. 3. Contrato de suministro de combustible y depósito de garantía para una operación militar internacional, ámbito de aplicación civil y mercantil. III. Embargo del depósito y competencia exclusiva en Bruselas I bis. 1. Las competencias exclusivas en materia de ejecución. 2. Embargo de depósito en Estado miembro distinto al del tribunal del foro, competencia no exclusiva. IV. A modo de conclusión, enmarcando la inmunidad de ejecución.

\section{El negocio jurídico y la finalidad, la compra de combustible para una operación internacional}

1. La operación militar ISAF (Fuerza Internacional de Asistencia para la seguridad), fue aprobada y creada por la ONU el 20 de diciembre de 2001 para reforzar la seguridad en Afganistán tras los atentados de las Torres Gemelas del 11 de septiembre. La OTAN asumió su mando el 11 de agosto de 2005. Para su gestión firmó el 1-2-06 y el 15-3-07 dos millonarios contratos BOA (Basic Ordering Agreements) de suministro de combustible entre los Cuarteles Generales Militares Internacionales, SHAPE ${ }^{1}$, y un pul de 3 compañías (alemana, suiza y de Emiratos Árabes Unidos), partes todas ellas en el proceso. Las dificultades de liquidez de la OTAN tras la disminución de aportaciones de los países miembros tras la crisis de 2008 provocaron la falta de cumplimiento de los plazos de pago, lo que motivó la firma de un contrato de depósito para asegurar el pago acordado ocho años después de la primera firma, en noviembre de 2014, materializado en el banco BNP Paribas, en Bruselas. Finalmente, el pago del combustible por parte de SHAPE no se produjo. Este incumplimiento motivó la demanda de las empresas suministradoras en Países Bajos, sede de SHAPE, el 1 de diciembre de 2015. El Tribunal de primera instancia, pese a la excepción de competencia por inmunidad de jurisdicción alegada por SHAPE se declara competente el 8 de febrero de 2017. En procedimiento no contradictorio autoriza el 14 de abril de 2016 el embargo del depósito en BNP Paribas, que se practica el 18 de abril de 2016 por el Juzgado de Primera Instancia belga competente por un importe de... ;200 millones de euros! Tras esto, y recurrida la primera resolución de competencia de 8 de febrero de 2017, el Tribunal de apelación de Países Bajos la revoca y se declara incompetente el 10 de diciembre de 2019 por inmunidad de jurisdicción de SHAPE respecto al contrato firmado. En tanto se desarrollaba este proceso, SHAPE pidió en el marco del procedimiento principal que se levantara el embargo preventivo, lo que se admitió en primera instancia el 12 de junio de 2017 y en segunda instancia el 27 de junio alegando que el interés de SHAPE en mantener la inmunidad de ejecución prevalecía sobre el interés de las sociedades en el cobro de su crédito. El embargo fue levantado.

2. Con semejantes hechos y caldo de cultivo, se cosecha el conflicto jurídico en el que el TJUE se pronuncia el 3 de septiembre de $2020^{2}$, por segunda vez en un asunto de similar en el mismo año ${ }^{3}$, sobre el alcance de la inmunidad de jurisdicción y de ejecución y su relación con el ámbito de aplicación del Reglamento Bruselas I bis ${ }^{4}$. Con esto asienta su doctrina sobre cuándo los negocios jurídicos celebrados por los estados o las organizaciones internacionales deben sustraerse o no al conocimiento de los tribunales

\footnotetext{
${ }^{1}$ El Estatuto de los Cuarteles Generales Militares Internacionales (SHAPE) como organización internacional con personalidad jurídica propia se regula en el Tratado del Atlántico Norte, firmado en París el 28 de agosto de 1952 . Su artículo 11 establece que "sin perjuicio de lo dispuesto en el artículo 8 del Convenio (Convenio entre las Partes del Tratado del Atlántico Norte relativo al Estatuto de sus Fuerzas, firmado en Londres el 19 de junio de 1951), un cuartel general supremo podrá ser parte, tanto demandante como demandada, en procedimientos judiciales". Aunque no tenga relación con el proceso señalamos que España, por ejemplo, se adhirió a este Estatuto mediante Instrumento de adhesión de 26 de julio de 1995 publicado en el BOE núm. 228 , de 23 de septiembre de 1995.

${ }^{2}$ Caso Supreme Site Services GmbH, Supreme Fuels, asunto C-186/19, ECLI:EU:C:2020:638.

${ }^{3}$ Nos parece especialmente significativa la existencia de dos resoluciones del TJUE sobre el mismo objeto de estudio en un mismo año, por lo que en el presente trabajo interrelacionaremos ambas sentencias y también estudiaremos la anterior a la de nuestro concreto objeto de estudio, la STJUE 7 mayo 2020, Caso Rina, asunto C-641/18, EU:C:2020:349.

${ }^{4}$ Reglamento (UE) n. ${ }^{\text {1 }}$ 1215/2012 del Parlamento Europeo y del Consejo, de 12 de diciembre de 2012 , relativo a la competencia judicial, el reconocimiento y la ejecución de resoluciones judiciales en materia civil y mercantil (DO 2012, L 351, p. 1).
} 
civiles europeos en aplicación del mismo. Llegado el procedimiento al Tribunal Supremo de los Países Bajos con la admisión de la inmunidad de ejecución y el levantamiento del embargo ejecutado en Bélgica por parte de los tribunales holandeses, al mismo le surgieron tres dudas esenciales que plantea al TJUE 5 . La primera, sobre si se había realizado una interpretación correcta de la inmunidad de ejecución y la misma se aplicaba al levantamiento del embargo acordado ejecutando un contrato de depósito en garantía de un contrato de suministro de combustibles para una operación de mantenimiento de la paz, y por ello quedaba fuera del ámbito de aplicación de Bruselas I bis. En segundo lugar, si por la ejecución del embargo trabado en Bélgica, se debía entender que este país contaba con competencia exclusiva para conocer la demanda de levantamiento del embargo a tenor del contenido del artículo 24.1.e de Bruselas I bis y por lo tanto los tribunales de Países Bajos debían abstenerse de conocer esta petición. Por último, y muy vinculada a las anteriores, si en caso de ser materia civil o mercantil, tiene relevancia la circunstancia de que la organización internacional haya basado sus pretensiones en la inmunidad de ejecución y si el órgano jurisdiccional está obligado a apreciar si procede la invocación de inmunidad de ejecución y si él debe examinar todos los elementos de que disponga, incluidas alegaciones u otra norma que pudiese ser aplicada.

3. Este planteamiento provoca que en el presente trabajo abordemos en primer lugar el análisis de la relación que existe entre el ámbito de aplicación en materias civiles y mercantiles del Reglamento Bruselas I bis definido en su artículo 1 con la inmunidad de jurisdicción y de ejecución de los estados y las organizaciones internacionales. La acotaremos enmarcando los márgenes en los que se mueve y por ello los supuestos en los que puede ser alegada por los estados o las organizaciones internacionales. No se nos esconde que una estrategia procesal relativamente habitual de estos es su alegación en la intención de sustraerse de la acción de la justicia en procedimientos de ámbito estrictamente privados, tal y como ocurrió en los dos supuestos resueltos por el TJUE en el presente año. En segundo lugar, analizaremos más brevemente cuándo el procedimiento de ejecución debe entenderse un procedimiento de competencia exclusiva por el que, una vez iniciado, ningún otro Tribunal de un Estado miembro se pude pronunciar sobre el mismo.

\section{El ámbito de aplicación de Bruselas I bis y la inmunidad de ejecución}

\section{1. Ámbito de aplicación material y civil y contrato de suministro militar}

4. El ámbito material de aplicación del Reglamento Bruselas I bis se regula, sin definirlo concretamente, en el artículo 1.1, señalando que el mismo regula las materias de ámbito civil y mercantil con independencia de la naturaleza del órgano jurisdiccional ${ }^{6}$, sin que sea aplicable en particular, a las materias fiscal, aduanera ni administrativa, ni a la responsabilidad del estado por acciones u omisiones en el ejercicio de su autoridad (acta iure imperii). Por ello este ámbito material se centra en el derecho privado patrimonial, con independencia de la naturaleza del órgano jurisdiccional que estudie el asunto, o de las partes implicadas, sean públicas o privadas. Lo relevante es la naturaleza de las relaciones jurídicas entre las partes. Se excluyen de su ámbito los litigios entre una autoridad pública y una persona de derecho privado, siempre que dicha autoridad actúe en el ejercicio del poder público, esto es, con facultades exorbitantes en relación con las normas aplicables en las relaciones entre particulares, y sea precisamente la intervención con estas facultades la que origine la relación jurídica. Con esta regulación el legislador europeo incorpora al Reglamento la propia jurisprudencia previa del $\mathrm{TJUE}^{7}$, y sitúa

\footnotetext{
${ }^{5}$ Se pueden consultar textualmente las extensas preguntas realizadas con dos subapartados las dos primeras en el párrafo 34 de la sentencia.

${ }^{6}$ En relación a la falta de definición del concepto "materia civil y mercantil” del Reglamento por parte del legislador, y su configuración como concepto autónomo de derecho europeo creado por el TJUE y que no remite al de ningún Estado miembro, vid. A.L. Calvo Caravaca y J. Carrascosa González, Derecho internacional privado Vol. II, Granada, Comares, decimoctava edición, 2018. pp. 719 y 720.

${ }^{7}$ Vid. P. De Miguel Asensio, "El nuevo reglamento sobre competencia judicial y reconocimiento y ejecución de resoluciones" La Ley, año XXXIV, nº 8013, p. 4.
} 
los litigios derivados de actividades de los estados iure gestiones en las que no haya incurso en ningún momento esas facultades exorbitantes subsumibles bajo su ámbito de aplicación ${ }^{8}$.

5. En el presente supuesto se estudia si se encuentra dentro de dicho ámbito de aplicación civil o mercantil un contrato de suministro de combustible entre una organización internacional que tiene como objeto posibilitar una operación militar de la OTAN y tres empresas del sector, en el que según la resolución estudiada se acordaron las típicas cláusulas de suministro de combustible con el régimen jurídico de los acuerdos que las partes asumieron respecto al suministro y el pago del combustible, contrato en el que nada se recogía sobre ningún tipo de ejercicio de facultades exorbitantes del Estado?. Tras la celebración del contrato, y una vez trabado un embargo de una elevada cantidad económica para el aseguramiento del pago del combustible servido, es el primer momento en el que, en la solicitud de levantamiento del embargo, SHAPE invoca la inmunidad de ejecución, no antes ${ }^{10}$.

\section{La inmunidad de ejecución de una organización internacional ante un impago}

6. Ante el problema planteado la pregunta clave es clara, diáfana, y de ella se derivan varias preguntas secundarias. ¿Puede aplicarse la inmunidad de ejecución al depósito constituido por el impago de una cuantía económica derivada de un contrato de suministro del combustible? ¿Actúa la organización internacional en el uso de su ius imperii por requerir el suministro para una operación militar de mantenimiento de la paz? ¿El objetivo público y político de la misión militar influye de forma determinante en el objeto del contrato? La inmunidad de jurisdicción es una excepción citada en el propio artículo 1.1. del Reglamento Bruselas I bis que sitúa fuera del ámbito material del mismo a los supuestos en los que los estados actúan aplicando el ius imperii enmarcado en el Derecho internacional público, y tiene como límite no vulnerar la normativa internacional de derechos humanos. Este es el motivo por el que el Tribunal de apelación de los Países Bajos señaló, al revocar la resolución de primera instancia de ejecutar el embargo, que dicha decisión no vulneraba el artículo 6 del Convenio Europeo para la Protección de los Derechos Humanos y de las Libertades Fundamentales, firmado en Roma el 4 de noviembre de $1950^{11}$.

7. La inmunidad de jurisdicción es una institución de protección de los estados o de las organizaciones internacionales que debe alcanzar a las acciones que desarrollan directamente vinculadas a su actividad pública, de representación y actuación política sobre sus intereses, que debe limitarse a este tipo de actuaciones y aplicarse de forma restrictiva, y que se extiende a la inmunidad de ejecución. Cierto es que los estados y las organizaciones internacionales suelen regularla en la intención de que las relaciones internacionales sean lo más fluidas posibles, y esto suele provocar aplicaciones excesivas y criticadas por la doctrina ${ }^{12}$, e incluso la existencia de acuerdos internacionales de reconocimiento de

${ }^{8}$ Vid. F.J. Garcimartín Alférez, Derecho internacional privado, Cizur Menor, Aranzadi, quinta edición, 2019, pp. 79 y 80, en el que señala diversos supuestos prácticos de la Jurisprudencia del TJUE en los que sí se aplica Bruselas I bis en demandas entre particulares y un estado.

${ }^{9}$ El régimen jurídico de estos contratos es complejo de determinar, pero si bien en él forman parte una organización internacional de derecho público y una entidad de derecho privado, el objeto del mismo dirige el acuerdo hacia la esfera del derecho privado únicamente, centrado en un suministro de combustible ordinario. Sobre la compleja realidad de la naturaleza jurídica de los contratos de las entidades públicas, vid. A. MARíN-LÓPEZ, "El régimen jurídico de los contratos concluidos por las organizaciones internacionales con personas privadas", AEDI, Vol. XIV, 1988, pp. 201 a 234.

${ }^{10}$ Respecto a la trascendencia del embargo y su naturaleza civil el Tribunal Supremo de los Países Bajos también consultó de forma muy acertada qué incidencia podía tener sobre la inclusión del litigio en la «materia civil y mercantil», el hecho de que el embargo preventivo fuera autorizado en virtud de un crédito nacido de una relación contractual que constituye el objeto del procedimiento sobre el fondo.

${ }^{11}$ Párrafo 27 de la sentencia analizada. En relación a los límites de esta excepción y la prohibición a los estados de denegación de justicia o de fijar normas de competencia que favorezcan injustificadamente a una de las partes utilizando de forma extensiva la institución jurídica de la inmunidad de jurisdicción, vid. A. RodríGuez Benot (director), Manual de Derecho internacional privado, Madrid, Tecnos, séptima, 2020, pp. 43 y 45.

${ }^{12} \mathrm{Al}$ respecto, véase el crítico análisis de González Vega sobre la inmunidad de ejecución según lo regulado en la Ley Orgánica 16/2015, de 27 de octubre, sobre privilegios e inmunidades de los Estados extranjeros, las Organizaciones Internacionales 
la inmunidad entre estados que, por su amplitud, son justificadamente puestos en entredicho ${ }^{13}$. Sobre si procedía la alegación de la inmunidad de ejecución en el presente procedimiento, lo que analizaremos en el siguiente epígrafe, debemos señalar que la misma es aplicable a estados, misiones diplomáticas y organismos internacionales, y se reconoce en los trámites de exequátur, y en el proceso de reconocimiento y ejecución de resoluciones extranjeras ${ }^{14}$, y es una excepción reconocida en la generalidad de los sistemas jurídicos comparados ${ }^{15}$. Por ello, si fuese aplicable a este contrato también se le debería reconocer a SHAPE.

\section{Contrato de suministro de combustible y depósito de garantía para una operación militar inter- nacional, ámbito de aplicación civil y mercantil}

8. El hecho debatido se centra en un contrato de suministro de combustible para los distintos medios empleados en una misión militar de seguridad en territorio extranjero. El objeto es la compra de combustible para que esos medios puedan desenvolverse en el terreno, no la finalidad última para la que después será empleado el mismo o sobre las consecuencias de la operación. Si bien la acción es militar y puede conllevar un determinado tipo de relación y responsabilidad por parte de lao organización militar con los afectados, el contrato previo de suministro para llevarla a cabo no tiene directa relación con los posibles efectos de la misma, sino únicamente con la relación mercantil que desarrolle quien necesita el combustible con el suministrador. Comparando con resoluciones similares del TJUE sobre casos en los que sí era aplicable la inmunidad de jurisdicción, no estamos ante el mismo supuesto de estudio de la responsabilidad de un estado resuelto por el TJUE en su Sentencia 15 febrero $2007^{16}$, en el que el Tribunal sí excluye del ámbito de aplicación de Bruselas I bis una acción derivada a una operación militar, en este caso en la Segunda Guerra mundial, pero vinculada a los daños sufridos por terceros durante el transcurso de la misma. En efecto, en el citado supuesto, se resuelve la reclamación de los daños causados por las fuerzas armadas de un estado en el territorio de otro, en concreto se trataba de la reclamación de daños por la masacre de civiles perpetrada por soldados de las fuerzas armadas alemanas el 13 de diciembre de 1943 y de la que fueron víctimas 676 habitantes del municipio de Kalavrita (Grecia), en la que los descendientes de los asesinados reclamaban al Estado alemán. La sentencia recoge expresamente ${ }^{17}$ que las operaciones de las fuerzas armadas constituyen sin lugar a dudas una de las manifestaciones características de la soberanía estatal, especialmente en la medida en que son decididas de modo unilateral e imperativo por las autoridades públicas competentes y están indisolublemente ligadas a la política

con sede u oficina en España y las Conferencias y Reuniones internacionales celebradas en España (BOE núm. 258, de 28 de octubre de 2015). Vid. J.A. GonZÁlez VEGA, "Inmunidades, Derecho internacional y tutela judicial en la Ley Orgánica 16/2015 de 27 de octubre, sobre inmunidades ijuego de espejos en el callejón del gato?, REDI, Vol. 68, 2016, 1, pp. 90 y 91. Sobre la extensión de la regulación de la inmunidad de ejecución de la misma, el autor señala que "hace prácticamente inalcanzable la posibilidad de una indemnización pecuniaria para el particular litigante".

${ }^{13} \mathrm{Al}$ respecto, un análisis crítico de esta aplicación excesivamente amplia de la excepción en la aún no en vigor Convención de las Naciones Unidas, de 2 de diciembre de 2004, sobre las inmunidades jurisdiccionales de los Estados y de sus bienes, lo encontramos en F.J. CARrera Hernández, "La inmunidad de ejecución de los estados en la Convención de las naciones unidas sobre las inmunidades jurisdiccionales de los estados y sus bienes", REDI, Vol. LVIII, 2006, 2, pp. 711 a 735. Sobre la Convención y la práctica jurisprudencial española, vid. J. FerRER Lloret, "La inmunidad de ejecución de LA Convención de 2004: un análisis desde la práctica de España”, AEDI, Vol. XXIII, 2007, pp. 3 a 61.

${ }^{14} \mathrm{Vid}$. F.J. Garcimartín alférez, Derecho internacional privado, op. cit., pp. 65. Reconocida en España, por ejemplo, en el artículo 1.e de la ya citada Ley Orgánica 16/2015, de 27 de octubre. En derecho comparado, por ejemplo, en relación a su también excesiva aplicación en el derecho venezolano por lo prescrito en el artículo 151 de su Constitución, vid. C. MADRID MarTínez, "Contratos con el estado: el fracaso del Derecho internacional privado de los contratos, caso venezolano", AEDIPr, T XVII, 2017, pp. 883 a 892.

${ }^{15}$ Sobre la inmunidad de jurisdicción analizada en el ámbito americano, vid. J.E. VARGaS y E. Rodríguez-WeIL, "La inmunidad de jurisdicción y ejecución de las organizaciones internacionales: un tema antiguo con relevancia actual”, AHLADI, Vol. 21, 2013, pp. 511-538. Y en relación a los bancos de desarrollo, vid. A. BJöRN, "La inmunidad de jurisdicción de los bancos multilaterales de desarrollo", REEI, No 22, 2011, pp. 1 a 31.

${ }^{16}$ Caso Lechourituou y otros, asunto C-292/05, ECLI:EU:C:2007:102.

${ }^{17}$ Párrafo 37, y tal y como defendió también el Abogado General en los apartados 54 a 56 de sus conclusiones. 
exterior y de defensa de los estados ${ }^{18}$. Pero se refiere clara y concretamente a los efectos de la operación sobre terceros, objeto de reclamación muy diferente del contrato de suministro de combustible previo entre la organización internacional o el estado que lo requiera con unas empresas del sector para poder abastecer a los medios empleados en la operación ${ }^{19}$.

9. Y entrando a analizar concretamente si el negocio jurídico en el que la organización internacional y los particulares participan en el presente supuesto es de ámbito público o privado, y comparando con ejemplos que ya ha señalado el TJUE sobre los supuestos en los se actúa en el ámbito público recogidos en la nota 19 , la sentencia de este mismo año de 7 de mayo de $2020^{20}$, establece que sí se encuentra dentro del ámbito civil y mercantil una demanda de indemnización interpuesta contra personas jurídicas de derecho privado que ejercen una actividad de clasificación y de certificación de buques por cuenta y por delegación de un estado tercero. En el supuesto, los perjudicados por el naufragio del buque Al Salam Boccaccio 98 entre los días 2 y 3 de febrero de 2006 en el mar Rojo y por el que murieron más de 1000 personas demandaron a las sociedades de clasificación y certificación Rina, responsables de las negligentes operaciones de clasificación y de certificación de buques llevadas a cabo por delegación y por cuenta de la República de Panamá para la matriculación del buque ${ }^{21}$. El Tribunal asienta, este mismo año y con solo cuatro meses de antelación con respecto a la sentencia que analizamos, que el hecho de que determinadas actividades tengan una finalidad pública (garantizar la seguridad de los pasajeros de un buque) o se realicen en interés de un estado, no constituye, en sí mismo, un elemento suficiente para calificarlas como actividades desempeñadas iure imperii, en la medida en que no correspondan al ejercicio de poderes exorbitantes en relación con las normas aplicables en las relaciones entre particulares. $Y$ aunque las actividades de clasificación y de certificación se rijan por convenios internacionales sobre seguridad en el mar y prevención de la contaminación marítima ${ }^{22}$, las operaciones de clasificación y de certificación fueron efectuadas por las sociedades Rina a cambio de una remuneración y en virtud de un contrato mercantil de derecho privado concluido directamente por el armador del buque Al Salam Boccaccio, según el cual, los servicios prestados por las sociedades Rina consistían únicamente en acreditar

${ }^{18}$ Y concluía en su fallo que una acción judicial ejercitada por personas físicas en un Estado miembro frente a otro Estado miembro, mediante la cual se pretende obtener reparación de los daños sufridos por los derechohabientes de las víctimas de la actuación de fuerzas armadas en el marco de operaciones bélicas en el territorio del primer Estado, no está comprendida en el concepto de «materia civil» del Reglamento Bruselas I bis.

${ }^{19}$ La misma sentencia establece en su párrafo 32 que tampoco se considera ámbito material civil y mercantil el procedimiento en el que un organismo nacional o internacional de derecho público que se encarga del cobro de las tasas que debe abonar una persona de derecho privado por la utilización de instalaciones y servicios del mismo, actúa en ejercicio del poder público, en particular, cuando esta utilización sea obligatoria y exclusiva y cuando la cuantía de las tasas, las modalidades de cálculo y los procedimientos de percepción se determinen de forma unilateral para los usuarios (STJUE 14 octubre 1976, Caso LTU, asunto 29/76, ECLI:EU:C:1976:137). Y en su párrafo 32 que lo mismo ocurre en el supuesto de un litigio entablado por el Estado administrador de los cursos de agua públicos contra la persona legalmente responsable con el objeto de recuperar los gastos causados por la retirada de un pecio, en cumplimiento de una obligación internacional, que haya sido efectuada o mandada efectuar por el administrador en ejercicio del poder público (STJUE 16 diciembre 1980, Caso Rüffer, asunto 814/79, ECLI:EU:C:1980:291).

${ }^{20}$ Caso Rina, asunto C-641/18, EU:C:2020:349.

${ }^{21}$ En el proceso, LG y otros reclaman la indemnización de los perjuicios materiales y morales derivada de la eventual responsabilidad civil de las sociedades Rina por el naufragio, alegando que en el origen del mismo se encuentran las negligentes operaciones de clasificación y de certificación del mencionado buque que las sociedades Rina llevaron a cabo, en virtud de un contrato celebrado con la República de Panamá para la obtención del pabellón de dicho Estado por el buque. Las sociedades demandadas alegan la falta de competencia del tribunal remitente invocando el principio de Derecho internacional de inmunidad de jurisdicción de los Estados extranjeros, ya que las operaciones de clasificación y de certificación que llevaron a cabo se efectuaron por delegación de la República de Panamá y, consecuentemente, son manifestación de las prerrogativas soberanas del Estado delegante.

${ }^{22}$ La actividad de clasificación de buques consiste en la expedición, por parte de una sociedad de clasificación elegida por el armador, de un certificado que acredita que el buque se ha proyectado y construido con arreglo a las normas de clase establecidas por esa sociedad según los principios establecidos por la Organización Marítima Internacional (OMI). La obtención del certificado de clasificación es requisito previo para la certificación obligatoria, que tiene lugar después de que el armador haya elegido el Estado del pabellón. La actividad de certificación consiste en la expedición de un certificado obligatorio por el Estado del pabellón o, en su nombre, por alguna de las organizaciones reconocidas por aquel para llevar a cabo inspecciones, así como en la expedición de determinados documentos o certificados de conformidad con el Convenio SOLAS. Ambas actividades de clasificación y de certificación son efectuadas a menudo por una misma sociedad (al respecto, con más detalle, párrafos 41 a 45 de la resolución). 
que el buque cumplía los requisitos establecidos en las disposiciones aplicables y, en caso afirmativo, en expedir los certificados correspondientes. Por todo ello estimó que las operaciones de clasificación y de certificación, como las realizadas en el buque Al Salam Boccaccio 98 por las sociedades Rina, por delegación y por cuenta de la República de Panamá, no pueden considerarse realizadas en el ejercicio de prerrogativas de poder público en el sentido del Derecho de la Unión, y se encuentran dentro del concepto de «materia civil y mercantil» del Reglamento Bruselas I bis ${ }^{23}$.

10. En nuestro supuesto, el contrato de suministro de combustible para poder asistir a los recursos empleados en la operación militar, en todo caso es un contrato o transacción mercantil, de ámbito privado, en el que la organización internacional adquiere un combustible a empresas del sector por un determinado precio, que se comprometen a surtirlo y por el que la organización militar se compromete a pagar su precio. Estamos, por ello, ante una relación jurídica de derecho privado entre los suministradores y SHAPE, en el marco de la cual ambas han asumido derechos y obligaciones libremente aceptados. El hecho de que las actividades tengan una finalidad pública (la acción militar de mantenimiento de la paz) o que se realice a través de una organización militar internacional, no constituye en sí mismo, al igual que en el caso Rina, un elemento suficiente para calificarlas como actividades desempeñadas iure imperii, en la medida en que el contrato de suministro no se encuadra en el ejercicio de poderes exorbitantes de la organización militar ni a prerrogativas de poder público en relación con las normas aplicables en las relaciones entre particulares. Se enmarca en una relación privada similar a cualquier otro suministro de combustible de las realizadas habitualmente por las suministradoras. Este supuesto, por ello, es para nosotros una excepción al principio de inmunidad de jurisdicción y de ejecución, bien interpretado por el TJUE que acertó en su resolución final, y que incluso también se debería encuadrar, en nuestro ordenamiento jurídico, en el supuesto de exención de la inmunidad recogida en el artículo 9 de la Ley Orgánica 16/2015, cuando establece que; "El Estado extranjero no podrá hacer valer la inmunidad ante los órganos jurisdiccionales españoles en relación con procesos relativos a transacciones mercantiles celebradas por dicho Estado con personas físicas o jurídicas que no tengan su nacionalidad" 24 .

11. También se encuadraría dentro del concepto de transacción privada de la Convención de las Naciones Unidas, de 2 de diciembre de 2004, sobre las inmunidades jurisdiccionales de los Estados y de sus bienes, que, si bien no ha entrado en vigor, desde luego es un elemento de análisis de interés para la configuración del actual supuesto. La misma, en su artículo 2.1.c, considera "transacción mercantil": “i) todo contrato o transacción mercantil de compraventa de bienes o prestación de servicios; (...) iii) cualquier otro contrato o transacción de naturaleza mercantil, industrial o de arrendamiento de obra o de servicios, con exclusión de los contratos individuales de trabajo". Y desde luego aun siendo el contrato BOA (Basic Ordering Agreements) un contrato complejo, se debe asimilar al de la prestación de un servicio de suministro de combustible, que en absoluto tiene directa relación con el ejercicio de facultad exorbitante alguna. Y, sobre el segundo contrato suscrito por las partes, si esa es la consideración del contrato de suministro, el embargo posterior del depósito acordado para el aseguramiento del

\footnotetext{
${ }^{23}$ Otros supuestos también considerados dentro de este concepto de materia civil y mercantil en el que intervenían estados u organizaciones internacionales fue, por ejemplo, las reclamaciones de un estado a un particular por los daños de un fraude fiscal basadas no en normativa de Derecho fiscal, sino en las acciones de responsabilidad civil (STJUE 12 setiembre de 2013, Caso $L T U$, asunto 49/12, ECLI:EU:C:2013:545). Misma doctrina aplican los Tribunales españoles. Por ejemplo, la STC 107/1992, 1 julio 1992, ECLI:ES:TC:1992:107, que considera no aplicable la inmunidad de jurisdicción ni de ejecución a las deudas surgidas por la prestación salarial de una empleada de la embajada de Sudáfrica en España. En el mismo sentido, respecto a empleado de la embajada de Guinea Ecuatorial en España, la STS 143/1986 10 febrero 1986, ECLI: ES:TS:1986:10867. Sobre la inmunidad de jurisdicción en nuestra jurisprudencia, vid. F.J. CABRERA HernÁndez, "La inmunidad de ejecución de los estados en la práctica jurisprudencial española”, AEDI, Vol. XXIII, 2007, pp. 63 a 99.

${ }^{24}$ Vid. J. Ferrer Lloret, "La Ley Orgánica 16/2015 sobre inmunidades: ¿aporta una mayor seguridad jurídica a los operadores del Derecho? Una valoración provisional" REDI, Vol. 68, 2016, 1, pp. 75 a 77. Sobre la configuración de la transacción mercantil como excepción, vid. M. GóMEZ JENE, "Inmunidad y transacciones mercantiles internacionales", $C D T$, vol. 3, nº 1 , pp. 155-178, y C. GutiérRez EsPADA, "Sobre la inmunidad de jurisdicción de los estados extranjeros en España, a la luz de la Ley Orgánica 16/2015, de 27 de octubre”, CDT, Vol. 8, nº 2, pp. 5 a 33, p. 14.
} 
pago de las cuantías adeudadas tiene el mismo carácter civil y mercantil que deriva del primer contrato $^{25}$ suscrito entre los suministradores y SHAPE ${ }^{26}$. De hecho, podemos señalar que la propia existencia del depósito denota el carácter privado de la relación entre las partes, y el aseguramiento por parte de la organización internacional del cumplimiento de sus obligaciones económicas de pago de lo debido dentro de este ámbito únicamente privado. La posterior alegación de la inmunidad de jurisdicción y de ejecución por la organización internacional para evitar la eficacia de la ejecución de las obligaciones a las que se sometió y que garantizó a la contraparte en el contrato a través de la constitución del depósito supone una quiebra a la naturaleza privada del contrato de suministro sobre el que incumplió sus obligaciones de pago.

\section{Embargo del depósito y competencia exclusiva en Bruselas I bis}

\section{Las competencias exclusivas en materia de ejecución}

12. El segundo de los aspectos analizados en la sentencia del TJUE, lateral al esencial de la inmunidad de jurisdicción y ejecución ya tratado, es el de la competencia exclusiva de la ejecución regulado en el artículo 24.5 del Reglamento Bruselas I bis, cuando señala que son exclusivamente competentes, sin consideración del domicilio de las partes, en materia de ejecución de las resoluciones judiciales, los órganos jurisdiccionales del Estado miembro del lugar de ejecución ${ }^{27}$. Consultaba el Tribunal Supremo de los Países Bajos si el hecho de que hubiese sido el Tribunal belga en Bruselas el que se había pronunciado inicialmente sobre la traba del embargo, no provocaba una competencia exclusiva en el sentido de que solo el mismo Tribunal podía conocer sobre la solicitud de levantamiento de dicho embargo, y en tal circunstancia los Tribunales de los Países Bajos deberían haberse abstenido de conocer sobre el mismo, y trasladar la decisión de dicho levantamiento al Tribunal belga.

13. Al respecto de la interpretación del carácter exclusivo de esta competencia el TJUE ha resuelto igualmente en el sentido de que dicha exclusividad de ejecución debe ser interpretada restrictivamente ${ }^{28}$, nunca de forma extensiva, debiendo interpretar el grado de proximidad de la ejecución con el procedimiento de forma estricta. Así, por ejemplo, en un supuesto de acción de oposición ejercitada por un acreedor disconforme con el reparto del producto obtenido con la subasta judicial de un inmueble, mediante la que se solicita, por una parte, que se declare que un crédito concurrente ha dejado de existir por haberse compensado y, por otra, que la constitución de la garantía real para asegurar dicho crédito es nula, el Tribunal declaró que el supuesto no es competencia exclusiva de los órganos jurisdiccionales del Estado miembro donde se encuentre el inmueble ni de los órganos jurisdiccionales del lugar de ejecución forzosa, y dicha acción puede ser resuelta por los Tribunales de otro Estado miembro $^{29}$. El sentido de esta competencia exclusiva se centra en el especial interés del legislador por

\footnotetext{
${ }^{25}$ Toda vez que la inclusión de una medida cautelar como es la traba del depósito en el ámbito civil y mercantil del Reglamento Bruselas I bis no depende de la naturaleza de la medida, sino de los derechos que garantiza respecto al fondo, y en este supuesto garantizaba los derechos de cobro respecto al contrato privado de suministro (entre otras, STJUE 26 marzo de 1992 , Caso Reichert y Kockler, C-261/90, EU:C:1992:149, apartado 32).

${ }^{26}$ El mismo esquema ya descrito a lo largo del trabajo se debe aplicar en el caso de la inmunidad de jurisdicción o de ejecución de una organización internacional, que tiene su fundamento en el Tratado internacional que la constituyó, que en el de la del Estado la tiene en el principio par in parem non habet imperium (un Estado no puede ser sometido a la jurisdicción de otro Estado).

${ }^{27}$ Sobre la extensión de dicho carácter exclusivo, vid. C. Esplugues mota, J.L. Iglesias Buhígues, G. Palao Moreno, Derecho internacional privado, Valencia, Tirant lo Blanch, decimocuarta edición, 2020, pp. 133 y 134.

${ }^{28}$ Sobre dicha jurisprudencia y sus consecuencias, vid. J.C. Fernández Rozas y S. SÁnchez Lorenzo, Derecho internacional privado, Cizur Menor, Cívitas, décima edición, 2018, p. 78.

${ }^{29} \mathrm{Vid}$. STJUE 10 julio 2019, Caso Reitbauer, asunto C-722/17, ECLI:EU:C:2019:557, párrafo 55, en el que establece que, toda vez que los actores no impugnaban los actos de las autoridades encargadas de la ejecución forzosa en sí mismos, la acción no presenta con dicha ejecución el grado de proximidad necesario para justificar la aplicación de la norma de competencia exclusiva prevista en el artículo 24, punto 5, del Reglamento Bruselas I bis.
} 
preservar a la jurisdicción de los tribunales de un Estado conocer determinados supuestos, por la vinculación con el mismo, que es únicamente de este Estado, hasta tal punto que no reconocerían ninguna resolución de un tercer Estado ${ }^{30}$ que hubiese dictado resolución previa vulnerando este competencia exclusiva $^{31}$. Todo ello por la vinculación que existe entre el supuesto de hecho concreto y el Estado en el que se ejecuta la acción.

\section{Embargo de depósito en Estado miembro distinto del tribunal del foro, competencia no ex- clusiva}

14. Asentada esta interpretación del grado de proximidad necesaria para considerar la competencia exclusiva para la ejecución ${ }^{32}$, podemos observar que en este supuesto no estamos en absoluto ante un grado de proximidad tal con la ejecución del embargo que provoque que solo el Tribunal belga podía conocer de todas las acciones ocurridas con el embargo tras su ejecución. El embargo se ejecuta en Bélgica porque SHAPE deposita el dinero de garantía del pago en el banco BNP Paribas de Bruselas, al igual que lo podía haber depositado en cualquier otro lugar. La relación con Bruselas es obligada por ser la sede del banco, pero únicamente se relaciona con él por este motivo. Muy al contrario, existen tantos o más vínculos de proximidad con Países Bajos por ser la sede de SHAPE en la que esta opera, el lugar del origen de la controversia y en el que se desarrolla el procedimiento que da como resultado el embargo posterior. Por otro lado, como vimos anteriormente, en el proceso en los Países Bajos, SHAPE no ataca únicamente la medida de embargo preventivo tomada por el tribunal belga, sino que solicita al órgano judicial de Países Bajos que declare la inmunidad de jurisdicción y ejecución en todo el proceso, y derivado de ella levante la medida del embargo preventivo acordado previamente por él mismo en un procedimiento sin carácter contradictorio y que se ha ejecutado en un tercer país, prohibiendo también que se inste en el futuro nuevos embargos. Este procedimiento inicial holandés no guarda relación con el embargo belga, no depende de él. Todo lo contrario, es el embargo belga el que se inicia ejecutando la resolución holandesa, por lo que la acción de la revocación de la decisión holandesa no está afectada por el carácter exclusivo de la ejecución llevada a cabo en Bélgica.

15. La duda le surge al Tribunal de los Países Bajos por varios motivos, pero el más sustancial lo situamos en el hecho de que SHAPE hubiese invocado la inmunidad de ejecución ${ }^{33}$. Sin embargo, ya expusimos con claridad que la inmunidad de ejecución no se puede considerar el elemento esencial de análisis en la relación entre las partes, sino que lo es la relación acordada entre ellos, que en este supuesto debemos vincular con claridad al ámbito civil y mercantil. Y a dicha acción relacionada con el levantamiento del embargo realizado en Bélgica, que trae causa de la acción privada que vincula a las partes iniciada en Países Bajos por ser la sede de SHAPE y donde se firmó el acuerdo, no le es aplicable la competencia exclusiva del artículo 24.5 del Reglamento Bruselas I bis respecto a los tribunales belgas según su naturaleza y la jurisprudencia del TJUE que lo ha concretado. Otra situación distinta será, en el futuro, una vez resuelto este procedimiento, la del levantamiento o nueva traba de hecho del embargo del dinero depositado en el BNP Paribas de Bruselas, que se debería realizar ejecutando una hipotética

\footnotetext{
${ }^{30}$ Vid. M. GuZmán Zapater (directora), Lecciones de Derecho internacional privado, Valencia, Tirant lo Blanch, 2019, p. 101.

${ }^{31}$ Vid. C. Carrillo Lerma, "Competencias exclusivas en materia civil y mercantil y libre circulación de decisiones en el espacio judicial”, CDT, Vol. 6, No 2, pp. 304-314, p. 313, analizando la STJUE 3 abril 2014, caso Weber c. Weber, Asunto C-438/12, ECLI:EU:C:2014:212.

${ }^{32}$ Porque, tal y como ya ha asentado el TJUE el artículo 24.5 comprende las acciones dirigidas a que se resuelva un litigio relativo al recurso a la fuerza, al apremio o a la desposesión de bienes muebles e inmuebles para garantizar la efectividad material de las resoluciones y de los actos (entre otras STJUE 10 julio2019, Caso Reitbauer y otros, C-722/17, EU:C:2019:577, apartado 52).

${ }^{33}$ Toda vez que duda sobre si son los órganos jurisdiccionales del Estado miembro en el que se ha ejecutado un embargo preventivo contra una organización internacional son quienes están en la mejor posición para apreciar si el embargo es contrario a la inmunidad de ejecución invocada por esta organización con fundamento en un tratado o en el Derecho internacional consuetudinario que vincula a ese Estado miembro.
} 
futura resolución holandesa ante el Tribunal belga sede del banco ${ }^{34}$, ejecutando esa otra nueva resolución de los Tribunales de los Países Bajos ${ }^{35}$.

\section{A modo de conclusión, enmarcando la inmunidad de ejecución}

16. La inmunidad de jurisdicción y de ejecución es una institución del Derecho internacional público de gran importancia para el correcto desenvolvimiento de la acción habitual de los estados en la defensa de sus intereses públicos. Está basada, en el caso de los estados, en el principio par in parem non habet imperium (un estado no puede ser sometido a la jurisdicción de otro estado), y en el caso de las organizaciones internacionales, en el Tratado internacional que la constituyó. Sin embargo, hemos analizado que no es infrecuente que los estados y las organizaciones internacionales en ocasiones abusen de la misma para intentar evitar las consecuencias privadas de sus actos, tanto en la legislación nacional e internacional como en los supuestos prácticos concretos.

17. En 2020 el TJUE ha continuado delimitando en dos ocasiones cuándo se aplica esta inmunidad de jurisdicción y cuándo no y por lo tanto las acciones de estados y organizaciones internacionales están dentro del ámbito de aplicación material civil y mercantil del Reglamento Bruselas I bis. Un contrato suministro de combustible para una operación militar celebrado entre una organización militar y un grupo de empresas suministradoras, aunque esté finalmente destinado al fin público de la operación, en su propia naturaleza es privado, y como tal se debe entender dentro del ámbito de aplicación del Reglamento. El posterior contrato de depósito de una cuantía económica celebrado entre ambas partes con el fin de asegurar el pago de las cuantías debidas por el contrato de suministro también tiene dicha naturaleza. Por último, igualmente tiene naturaleza civil y mercantil el contrato de clasificación y certificación de buques ejecutados por una sociedad privada con el armador del buque a cambio de remuneración, aunque se realicen por delegación y por cuenta de un estado.

18. El acuerdo de traba o de levantamiento de un embargo de un depósito monetario acordado por un Tribunal de un Estado miembro, pero ejecutado por los Tribunales de otro Estado miembro distinto en el que tiene el domicilio el banco en el que está depositado el dinero, no supone una competencia exclusiva de este otro Estado miembro de ejecución. Esta falta de consideración de foro de competencia exclusiva se produce toda vez que la ejecución del embargo trae causa de un negocio jurídico privado anterior y el grado de proximidad de la ejecución con el país de depósito del dinero no es tal que provoque la consideración de un foro exclusivo con preferencia al del Tribunal del Estado miembro que acordó inicialmente el embargo.

${ }^{34}$ Vid. A.L. Calvo Caravaca y J. Carrascosa González, Derecho internacional privado Vol. II, op. cit., pp. 744 y 745, que señalan que el artículo 24.5 solo es aplicable al proceso de ejecución propiamente dicha de una decisión judicial, no sobre la base sobre la que se asienta dicha ejecución.

${ }^{35}$ Problema distinto en el que no podemos entrar por no ser objeto del presente trabajo sería la posible admisión por el Tribunal del Estado miembro ejecutante de la orden, atendiendo a la naturaleza jurídica de dicho embargo y su posible incompatibilidad con principios esenciales de su ordenamiento jurídico, como podría ocurrir en algunos supuestos con ciertas figuras jurídicas del derecho anglosajón. Sobre dicha interesante cuestión práctica, Vid. J. Zarzalejos Herrero, "La orden de embargo preventivo extraterritorial en Derecho inglés", $C D T$, Vol. 11, № 1, pp. 603-626. 